\title{
Reflective Journal Writing and Classroom Performance: Improvement and Correlation among Pre-Service Mathematics and Science Teachers
}

\author{
Areej Isam Barham, PhD and Elham Ghazi Mohammad , PhD \\ College of Education \\ Qatar University, Doha, Qatar \\ Ruba Miqdadi, PhD \\ Faculty of Education \\ Yarmouk University, Irbid, Jordan
}

\begin{abstract}
This study investigated improvements in reflective journal writing and classroom performance among pre-service mathematics and science teachers as well as the correlation between reflective journal writing and classroom performance. The study was conducted during a clinical experience where pre-service mathematics and science teachers were placed in 10-week field-based learning experiences during their final semester of the Bachelor of Education degree in Primary Education. Study participants included 30 pre-service mathematics and science primary school teachers, and the study was conducted during the two academic semesters of spring 2017 and fall 2017. A quantitative research approach was followed, and descriptive statistics were determined using Statistical Packages for Social Sciences (SPSS). Data were gathered using two research instruments: the Clinical Experience Evaluation (CEE) survey and a weekly reflective journal. The results of the study revealed that within the 10-week study period, participants improved, with statistically significant differences $(p<0.05)$, in most dimensions of reflective writing (reflectivity, thoroughness, variety, growth), with the exception of the professionalism dimension. Participants also improved, with statistically significant differences $(p<0.05)$, in all domains related to classroom performance, except for the assessment domain. Furthermore, throughout the clinical experience, participants showed improvement in the reflective journal dimensions. Finally, we observed that the variety dimension of reflective journal writing contributed statistically to the development of classroom performance.
\end{abstract}

Keywords: Reflective journal; Classroom performance; Pre-service teachers. 


\section{Introduction}

Learning happens when the learner becomes fascinated by information, thinks about it, makes sense of it, and equates it with what they already know. In line with this, a reflective journal is a method for thinking critically and logically about self-development. Göker (2016, p. 64) stated that

"Journal writing, within this context, is considered to be new learning tools for teachers to create an awareness on their current practice. Through reflective journals aiming to create critical environments, teachers can provide other teachers with an opportunity to reflect on their existing considering other optional methods and develop reflective leadership."

The implications of reflective journal writing can be traced back to the work of John Dewey (1933), who identified reflective inquiry as being the "active, persistent, and careful consideration of any belief or supposed form of knowledge in light of the grounds that support it and further conclusions to which it tends." (p. 9)

Dewey (1933) claimed that teaching experience is important as a stimulus for reflective thinking, as it requires the identification of problems and their possible solutions that can be implemented in future teaching practices. Extending Dewey's claim, Davis (2006) argued that there is a link between teaching and reflection, whereby fruitful reflection through writing lets pre-service teachers express their opinions about their teaching experiences. As teachers continually encounter unexpected situations and individual differences among their students (Berry, 1999). More specifically, after teachers observe what is actually happening in the classroom, they keep their notes in journals. These notes include different reflections, which provide them with opportunities to identify their needs for class practice enhancements and improve reflective practice (Göker, 2016).

Furthermore, practicing reflective thinking by writing a reflective journal can directly impact professional growth and make connections between mentoring practices and writing reflections (Sempowicz \& Hudson, 2012). Moreover, writing a critical reflective journal about the development of their actual teaching experience is considered a vital skill (Bell \& Gillet, 1996). Furthermore, Swafford, Jones, Thornton, Stume, and Miller (1999) argued that reflective writing facilitates enhanced confidence in teaching mathematics and helps teachers shift the teaching process from traditional textbook-based instruction towards problem-solving and hands-on learning.

For these reasons, improving future teachers' capability to reflect is a key goal of teacher preparation programs (Hatton \& Smith, 1995). Reflection through writing leads pre-service teachers to anatomize their training experience as they rethink and revise it (Isikoglu, 2007). Reflective journal writing has been identified as an essential tool to promote high-level critical thinking within preservice teacher preparation programs (Lindroth, 2015). For these reasons, it is a common practice in many teacher training programs and is considered a critical 
component of development in all aspects of the progress of pre-service teachers (Morrison, 2009).

The existing literature has thoroughly explored the field of reflective thinking, teaching, and learning, including the efficacy of reflective journaling for teachers. Some researchers have found that pre-service teachers who used reflective writing in their preparation programs showed improvement in their teaching skills (Heichel \& Miler, 1993; Risko, Roskos \& Vukelich, 2002). In the same domain, Davis (2006) argued that pre-service teachers could assimilate their ideas about their teaching in their written reflections. Gikandi (2013) conducted a case study in which 12 post-graduate teachers at a New Zealand university wrote their reflections in an open online reflection journal (ORJ). The study evaluated the extent to which the ORJ stimulated self-assessment and how the reflections fostered learning, showing that an ORJ offers a good tool to facilitate both productive self-assessment and formative assessment. Meanwhile, Knapp (2012) used her students' reflective journals to study their educational experiences based on her assumption that journal writing helps instructors to be more understanding of their students' learning experiences.

Other studies of the relationship between reflective writing and teaching go into more depth on the topics that pre-service teachers learn about through reflective writing, its impact on their beliefs and attitudes, and what it reveals about the learning process. For example, Uline, Wilson, and Cordry (2004) investigated 86 pre-service teachers involved in secondary practicum experiences in which they were required to complete 85 hours in classrooms. During the practicum, the pre-service teachers were engaged in many activities, including writing a final reflection journal entitled "My most significant learning experience." In their responses, the pre-service teachers identified a wide variety of topics: specifically, behavior management, teacher flexibility, and time management were ranked as the most significant issues encountered during clinical practice. In order to uncover the effect of reflective journal writing on pre-service science teachers' beliefs, Love (2001) had participants keep daily reflective journals and complete the Science Teaching Efficacy Belief Instrument. Data were collected through surveys, studied journals, lesson plans, observations, and discussions. The results showed that reflective journal writing did influence the pre-service teachers' beliefs towards science teaching, and they also revealed that preservice teachers believed that science teaching could be an enjoyable process for both students and teachers and that they subsequently felt more confident about modifying lessons. A qualitative research study carried out by Shoffner (2008) explored using weblogs with pre-service teachers, who completed 263 weblogbased reflections and participated in interviews as an additional data source. The results showed that pre-service teachers engaged in an alternative form of reflection that co-existed with established structures of reflective practice. In the same domain, Davis (2006) conducted research to determine how pre-service teachers synthesize their ideas about learners and instruction, showing that this reflection can aid new teachers in integrating these ideas and developing a multifaceted view of teaching. 
Researchers have also made connections between reflective journaling and teacher performance. Cengiz and Karatas (2015) investigated the effects of reflective journaling on pre-service chemistry teachers' achievement over eight weeks. Pre- and post-tests were administered in addition to interviews, and results showed that the reflective journal activities enhanced pre-service teachers' achievement scores and had positive effects on their meta-cognition skills and learning. Hatton and Smith (1995) investigated pre-service teachers' reflections using an analysis methodology to examine the content and level of their reflection and how it related to their professional development. The results showed that supporting reflective skills can positively affect pre-service teachers' professional development.

The literature review has addressed the impact of reflective journal writing on classroom performance. Numerous studies have noted that practicing reflective thinking through reflective journals contributes to the development of teaching skills and classroom performance (Gungor, 2016; Cohen-Sayag \& Fischl, 2012; Rodman, 2010; Gonen, 2016). For example, in a study conducted by Gungor (2016), which aimed to enhance reflective practices for pre-service English teachers via microteaching sessions, reflective journals, and lesson plans, it was found that reflecting practices and sharing additional comments on actual teaching through videos and diaries allowed pre-service teachers the opportunity to identify their strengths and weaknesses. It also allowed them to achieve deeper reflection, evaluate, understand, and improve their reflective teaching practices, and reduce the gap between idealistic and real teaching considerations. In another study, Cohen-Sayag and Fischl (2012) explored changes in levels of pre-service teachers' reflective writing and examined the impact of these changes on their teaching success. The study compared two groups of teachers - one that journaled and the other that did not. Journal analysis showed three reflective levels of explanations: descriptive, comparative, and critical. The study found that both groups improved in descriptive levels of explanations, but only the reflective group was found to have improved their ability for higher levels of reflective explanations. The results also showed a positive correlation between reflective writing and teaching skills.

Similarly, another researcher Rodman (2010), found that having pre-service teachers engage in reflection as part of their teacher preparation experiences had a positive impact on improving pedagogical knowledge, teaching performance and professional development. In another study, Gonen (2016) explored the effect of engaging pre-service teachers in a reflective reciprocal peer coaching exercise on the development of reflective thinking skills. Gonen investigated whether such experiences could be linked to changes in teacher reflectivity. Using a mixed-method research design, the study showed that pre-service teachers advanced their reflectivity throughout the reflective reciprocal peer coaching practice experience.

The overarching goal of these studies was to enhance teacher education by helping pre-service teachers practice what they had learned. Moreover, they aimed to highlight the benefit of reflective journals, which enhance pre-service 
teachers' teaching methods when used as part of teacher practicum education. However, no studies to date have examined the specific relationship between reflective journaling and teacher performance in particular dimensions. The innovation of this current study lies in its investigation of the improvement in both reflective journal writing, and classroom performance among participating pre-service teachers during a clinical experience wherein they were placed on 10-week field-based learning experiences during their final semester of the Bachelor of Education degree in Primary Education. Our research thus explores the improvement of pre-service teachers' reflective journal writing in five dimensions (reflectivity, thoroughness, variety, growth, and professionalism) and the improvement in their classroom performance. To achieve the aims of the study, we address the following research questions:

1. To what extent did pre-service mathematics and science teachers improve their reflective journal writing and classroom performance during the clinical experience?

2. Do the improvements in reflective journal writing correlate with improvements in the classroom performance of pre-service teachers?

\section{Method}

\section{Study context and participants}

The College of Education at Qatar University offers a math- and science-focused primary education program. The mission of the program is to prepare graduates who are skilled, reflective, and dedicated practitioners in mathematics and science primary education and leaders in providing a world-class education to the students in schools.

As pre-service teachers develop through their clinical internship programs, the focus of their training increasingly shifts towards field-based learning experiences. Therefore, pre-service teachers do 10-week clinical experience placements during their final semester of the Bachelor of Education degree in Primary Education. This clinical experience offers them the chance to reflect on their improved knowledge and to develop and assess their classroom skills.

The College of Education places pre-service teachers in local independent schools where they are supervised by a mentor teacher. The pre-service teachers also complete activities during their clinical experiences that require them to apply new skills and to reflect on learned skills. During the clinical experiences, academic supervisors and mentors observe the pre-service teachers in their classrooms to provide them with ongoing feedback as well as to conduct two formal evaluations in the form of classroom performance assessments. The first is used as a formative assessment and is considered a midterm exam, and both the academic supervisors and mentors participate in the evaluation process. At the end of the semester, a second evaluation is used as a summative assessment and is considered the final exam. Furthermore, during the 10-week semester of the clinical experience, the pre-service teachers are asked to reflect on their experiences in the classroom by writing a weekly reflective journal entry, which is submitted to both the academic supervisors and the classroom mentors. The 
study participants were 30 pre-service mathematics and science primary school teachers. The study was carried out over two academic semesters: spring 2017 and fall 2017.

\section{Instrumentation}

Two research instruments were utilized in the study. To evaluate the classroom performance of the pre-service mathematics and science teachers, the Clinical Experience Evaluation (CEE) survey was utilized as a midterm and final assessment tool. The CEE survey includes 51 items rated on a four-point Likerttype scale arranged as follows: $4=$ target, $3=$ satisfactory, $2=$ needs improvement and 1 = unsatisfactory. The $51 \mathrm{CEE}$ survey items were distributed over nine classroom performance domains to be assessed, namely: lesson planning and materials needed; teaching and classroom management; language, literacy, and numeracy; learning environment; relevance and extensions; information and communication technology; assessment; using pedagogy to improve learning; and subject area knowledge.

The second research instrument used in this study was developed every week by the pre-service teachers themselves. This study utilized weekly reflective journal writing to examine the progress of the pre-service teachers' reflective skills. The weekly journals included reflective writing about their personal thoughts, feelings, and insights into their teaching experience and events. Moreover, these reflections were based on many different experiences and provided extensive perspectives on many aspects related to teaching and learning. Meanwhile, it also allowed for high confidentiality and ethical standards. This method also maintained respect for the teaching profession while also clearly demonstrating the teachers' growth in skills, understanding, and professionalism. A reflective journal writing rubric was utilized to assess the skill of reflective journal writing, including the five dimensions of reflectivity, thoroughness, variety, professionalism, and growth; these were rated as $4=$ target, 3 = satisfactory, 2 = needs improvement, and $1=$ unsatisfactory.

\section{Validity and reliability of the research instruments}

To establish the validity of the two research instruments, i.e., the CEE survey and the reflective journal writing rubric, we gave them to a group of seven referees who were members of the Clinical Partnerships and Practice Committee for the National Council for the Accreditation of Teacher Education (NCATE). In addition, the survey and the rubric were field-tested on 10 pre-service teachers who were not among the study participants. Changes indicated by the validation panel and the field testing were considered during the development phase of the research instrument, and as a result, some items of the CEE survey were deleted, and others were added. In addition, some changes were made to the reflective journal writing rubric. To satisfy the reliability of the research instruments, the internal reliabilities (Cronbach's alpha coefficient) were established for the dimensions of the CEE survey. The calculated alpha coefficients ranged from 0.82 to 0.91 , thus indicating a satisfactory level of reliability (Creswell, 2014). Moreover, to satisfy the reliability for reflective journal writing rubrics, we calculated the rater (or scorer) reliability, which refers to the consistency of the scores assigned by two independent raters 
(Barbara \& Jon, 2000). The academic supervisors and mentors were asked to assess the reflective journals for five pre-service teachers who were not included in the sample. The interrater reliabilities were calculated, and they ranged from 0.87 to 0.96 , indicating the high reliability of the reflective journal writing rubric.

After designing the research instrument and before utilizing it, the researchers obtained Research Ethics Approval No. QU-IRB 811-E/17 from the University Institutional Review Board, which gave official permission to collect data for this study.

\section{Data Analysis}

This study followed a quantitative research approach. Descriptive statistics were utilized using Statistical Packages for Social Sciences (SPSS). Cronbach's alpha coefficients were determined for the items of the CEE survey, and the whole survey was calculated to verify the reliability of the research instrument. In addition, the interrater reliabilities were calculated to verify the reliability of the reflective journal writing rubric.

We utilized various statistical tests to answer the first research question examining the improvements of pre-service mathematics and science teachers in their reflective journal writing and classroom performance over time during the clinical experience. The improvements in reflective journal writing were examined by calculating the means and standard deviations, which were then used in the repeated measures ANOVA analysis. The Greenhouse-Geisser test was used to compare the five measures of the mean scores for each of the five dimensions of reflective journal writing during the 10 weeks of clinical experience. This was done because the Greenhouse-Geisser test is suitable for assessing change in outcomes based on three or more observations over time or within-subjects where the means and standard deviations should be reported for each observation of the outcome with Greenhouse-Geisser corrections (Greenhous-Geisser, n.d.) In addition, the means, standard deviations, and paired sample t-tests were examined to determine whether there were any statistically significant differences between the midterm and final pre-service classroom performances by comparing the mean scores of the mid and final CEE surveys. Moreover, we used pairwise comparisons to examine whether there were any statistically significant differences for the mean scores of the multiple comparisons of the five measures for each dimension of reflective journal writing during the clinical experience.

To shed light on the second research question, which asks whether the improvements in the reflective journal writing correlated with the improvements in the pre-service teachers' classroom performance, a linear regression analysis was utilized for the data representing the last measures of the reflective journal writing mean scores and the final CEE survey mean scores. 


\section{Findings}

Improvement of pre-service teachers' reflective journal writing and classroom performance

To examine the improvement of the pre-service mathematics and science teachers in their reflective journal writing using means and standard deviations as well as through repeated measures ANOVA analysis, we utilized Greenhouse-Geisser tests for each dimension of reflective journal writing, namely, reflectivity, thoroughness, variety, professionalism, and growth.

Findings related to the improvement of measure 1: Reflectivity

As shown in Table 1, the mean scores of the reflectivity dimension increased during the clinical experience, from 2.87 to 3.73 .

Table 1: Means and standard deviations of the pre-service teachers' scores in the reflectivity dimension

\begin{tabular}{lll}
\hline Reflectivity & Mean & $\begin{array}{l}\text { Std. } \\
\text { Deviation }\end{array}$ \\
\hline W1-R & 2.87 & 0.629 \\
\hline W3-R & 2.93 & 0.521 \\
\hline W5-R & 3.27 & 0.583 \\
\hline W7-R & 3.47 & 0.507 \\
\hline W9-R & 3.73 & 0.450 \\
\hline
\end{tabular}

To examine the overall significant difference between the means at the different time points for the reflectivity dimension, we utilized the Greenhouse-Geisser test to explore the effects within subjects. The results revealed that there were statistically significant differences among the five mean scores of the reflectivity dimension in reflective journal writing during the 10 weeks of the clinical experience. As the data did not conform to the assumption of sphericity, the Greenhouse-Geisser row values were considered. The findings from the ANOVA with repeated measures and a Greenhouse-Geisser correction revealed that the mean scores for reflectivity were statistically significantly different $(\mathrm{F}(3.156,91.538)=16.313, \mathrm{p}<0.05)$ with a partial eta squared effect size of 0.360 .

The results indicated overall significant differences in the means, but to know where those differences occurred, the Bonferroni post hoc test (pairwise comparisons) was utilized (Table 2) to determine which specific means differed. 
Table 2: Pairwise comparisons test for measure 1: Reflectivity

\begin{tabular}{|c|c|c|c|c|c|c|}
\hline \multirow{2}{*}{\multicolumn{2}{|c|}{ (I) Reflectivity }} & \multirow{2}{*}{$\begin{array}{c}\text { Mean } \\
\text { Difference } \\
\text { (I-J) }\end{array}$} & \multirow{2}{*}{$\begin{array}{l}\text { Std. } \\
\text { Error }\end{array}$} & \multirow{2}{*}{ Sig. ${ }^{b}$} & \multicolumn{2}{|c|}{$\begin{array}{l}\text { 95\% Confidence Interval } \\
\text { for Difference }\end{array}$} \\
\hline & & & & & $\begin{array}{l}\text { Lower } \\
\text { Bound }\end{array}$ & $\begin{array}{l}\text { Upper } \\
\text { Bound }\end{array}$ \\
\hline \multirow[t]{4}{*}{1} & 2 & -0.067 & 0.117 & 0.573 & -0.306 & 0.172 \\
\hline & 3 & $-.400^{*}$ & 0.156 & 0.016 & -0.719 & -0.081 \\
\hline & 4 & $-.600^{*}$ & 0.149 & 0.000 & -0.904 & -0.296 \\
\hline & 5 & $-.867^{*}$ & 0.142 & 0.000 & -1.156 & -0.577 \\
\hline \multirow[t]{4}{*}{2} & 1 & 0.067 & 0.117 & 0.573 & -0.172 & 0.306 \\
\hline & 3 & $-.333^{*}$ & 0.130 & 0.016 & -0.599 & -0.068 \\
\hline & 4 & $-.533^{*}$ & 0.124 & 0.000 & -0.788 & -0.279 \\
\hline & 5 & $-.800^{*}$ & 0.111 & 0.000 & -1.028 & -0.572 \\
\hline \multirow[t]{4}{*}{3} & 1 & $.400^{*}$ & 0.156 & 0.016 & 0.081 & 0.719 \\
\hline & 2 & $.333^{*}$ & 0.130 & 0.016 & 0.068 & 0.599 \\
\hline & 4 & -0.200 & 0.130 & 0.136 & -0.467 & 0.067 \\
\hline & 5 & $-.467^{*}$ & 0.115 & 0.000 & -0.701 & -0.232 \\
\hline \multirow[t]{4}{*}{4} & 1 & $.600^{*}$ & 0.149 & 0.000 & 0.296 & 0.904 \\
\hline & 2 & $.533^{*}$ & 0.124 & 0.000 & 0.279 & 0.788 \\
\hline & 3 & 0.200 & 0.130 & 0.136 & -0.067 & 0.467 \\
\hline & 5 & $-.267^{*}$ & 0.082 & 0.003 & -0.435 & -0.099 \\
\hline \multirow[t]{4}{*}{5} & 1 & $.867^{*}$ & 0.142 & 0.000 & 0.577 & 1.156 \\
\hline & 2 & $.800^{*}$ & 0.111 & 0.000 & 0.572 & 1.028 \\
\hline & 3 & $.467^{*}$ & 0.115 & 0.000 & 0.232 & 0.701 \\
\hline & 4 & $.267^{*}$ & 0.082 & 0.003 & 0.099 & 0.435 \\
\hline
\end{tabular}

Based on estimated marginal means

*. The mean difference is significant at the .05 level

b. Adjustment for multiple comparisons: Least significant difference (equivalent to no adjustments).

Table 2 shows that the findings obtained using the pairwise comparisons test revealed statistically significant mean score differences in pre-service mathematics and science teachers' journal writing in the reflectivity dimension. The differences started between the first and fifth weeks (third measure), and between the seventh week (fourth measure) and the ninth week (final measure), while there were no statistically significant differences in the mean scores between the first week (first measure) and the third week (second measure). No statistically significant differences were found between the fifth week (third measure) and the seventh week (fourth measure). 
Findings related to the improvement of measure 2: Thoroughness

As shown in Table 3, the mean scores of the thoroughness dimension increased during the clinical experience, from 2.24 to 3.55 .

Table 3: Means and standard deviations of the pre-service teachers' scores in the thoroughness dimension

\begin{tabular}{ccc}
\hline Thoroughness & Mean & $\begin{array}{c}\text { Std. } \\
\text { Deviation }\end{array}$ \\
\hline W1-T & 2.24 & 0.511 \\
\hline W3-T & 2.76 & 0.511 \\
\hline W5-T & 3.10 & 0.673 \\
\hline W7-T & 3.31 & 0.604 \\
\hline W9-T & 3.55 & 0.572
\end{tabular}

To examine the overall significant difference between the means at the different time points for the thoroughness dimension, we utilized the Greenhouse-Geisser test to explore the effects within subjects. The results revealed statistically significant differences among the five mean scores of the thoroughness dimension in the reflective journal writing during the 10 weeks of the clinical experience. The findings achieved using an ANOVA and repeated measures with a Greenhouse-Geisser correction revealed that the mean scores for thoroughness were statistically significantly different $(\mathrm{F}(3.114,87.180)=30.199, \mathrm{p}$ $<0.0005)$ with a partial eta squared of 0.519 .

The results indicated overall significant differences in the means, but to know where those differences occurred, the Bonferroni post hoc test (pairwise comparisons) was utilized (Table 4) to determine which specific means differed.

Table 4: Pairwise comparisons test for measure 2: Thoroughness

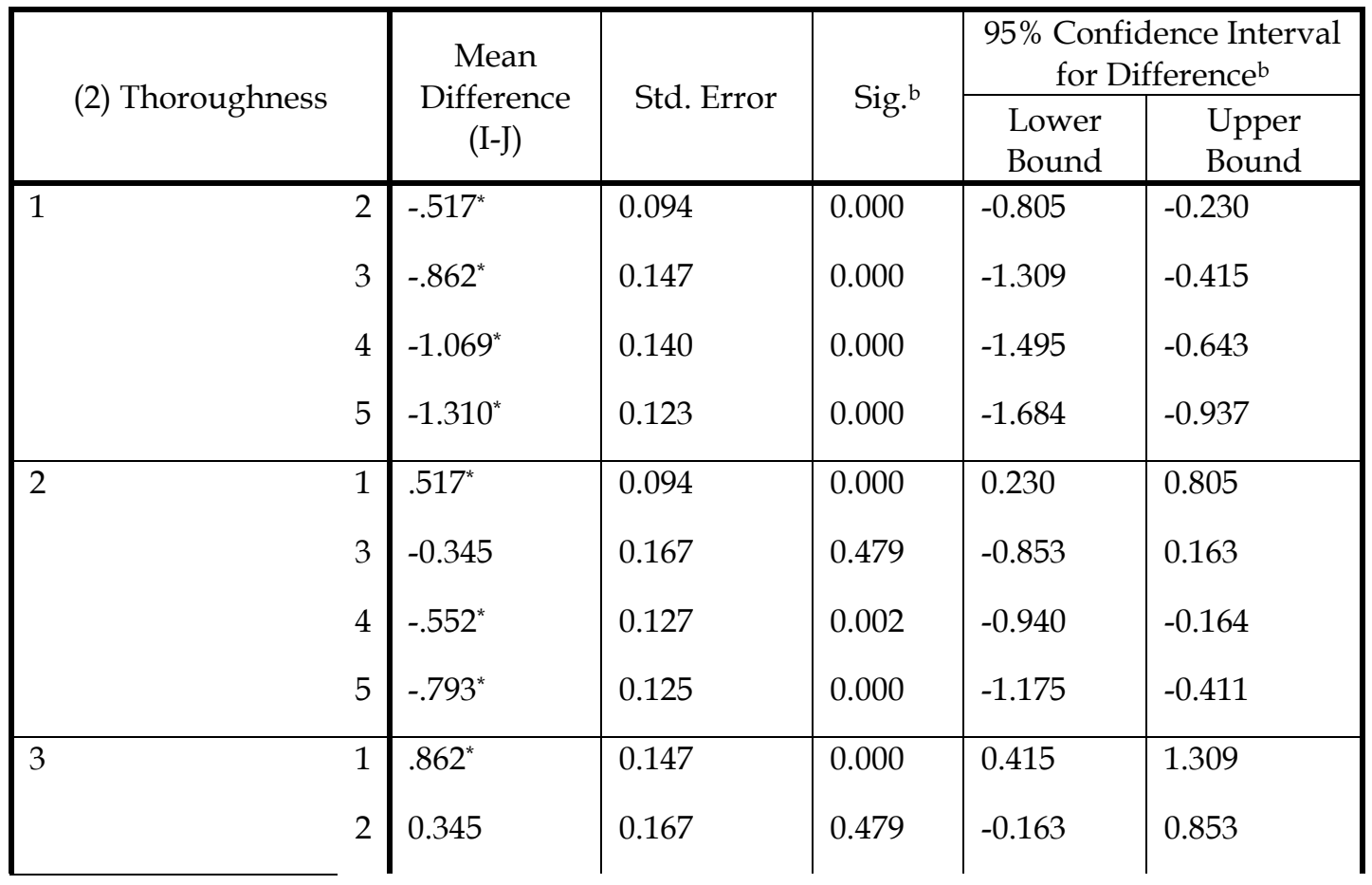




\begin{tabular}{|ll|l|l|l|l|l|} 
& 4 & -0.207 & 0.135 & 1.000 & -0.618 & 0.204 \\
& 5 & $-.448^{*}$ & 0.137 & 0.028 & -0.865 & -0.032 \\
\hline 4 & 1 & $1.069^{*}$ & 0.140 & 0.000 & 0.643 & 1.495 \\
& 2 & $.552^{*}$ & 0.127 & 0.002 & 0.164 & 0.940 \\
& 3 & 0.207 & 0.135 & 1.000 & -0.204 & 0.618 \\
\hline 5 & 5 & -0.241 & 0.107 & 0.322 & -0.568 & 0.085 \\
& 1 & $1.310^{*}$ & 0.123 & 0.000 & 0.937 & 1.684 \\
& 2 & $.793^{*}$ & 0.125 & 0.000 & 0.411 & 1.175 \\
& 3 & $.448^{*}$ & 0.137 & 0.028 & 0.032 & 0.865 \\
& 4 & 0.241 & 0.107 & 0.322 & -0.085 & 0.568 \\
\hline
\end{tabular}

Based on estimated marginal means.

*. The mean difference is significant at the .05 level.

b. Adjustment for multiple comparisons: Least significant difference (equivalent to no adjustments).

As shown in Table 4, the findings obtained using the pairwise comparisons test revealed statistically significant differences in the mean scores of the pre-service mathematics and science teachers' journal writing in the thoroughness dimension. The differences started between the first week and the third week (second measure), and in contrast with measure 1 (reflectivity), they continued throughout the whole period. Meanwhile, there were no statistically significant differences in the mean scores of the pre-service teachers' journal writing in the thoroughness dimension between the third week (second measure) and the fifth week (third measure). No statistically significant differences were found between the fifth week (third measure) and the seventh week (fourth measure) or between the seventh week (fourth measure) and the ninth week (fifth measure).

Findings related to the improvement of measure 3: Variety

As shown in Table 5, the mean scores of the variety dimension increased during the clinical experience, from 2.43 to 3.37 .

Table 5: Means and standard deviations of the pre-service teachers' scores in the variety dimension

\begin{tabular}{c|c|c|}
\hline \multicolumn{1}{c}{ Variety } & Mean & Std. Deviation \\
\hline W1-V & 2.43 & 0.568 \\
W3-V & 2.87 & 0.507 \\
W5-V & 3.10 & 0.548 \\
W7-V & 3.43 & 0.568 \\
W9-V & 3.37 & 0.556 \\
\hline
\end{tabular}

To examine the overall significant difference between the means at the different time points for the variety dimension, we utilized the Greenhouse-Geisser test to 
explore the effects within subjects. The results revealed statistically significant differences among the five mean scores of the variety dimension in the reflective journal writing during the 10 weeks of the clinical experience. The findings were analyzed using an ANOVA and repeated measures with a Greenhouse-Geisser correction, revealing that the mean scores for variety were statistically significantly different $(\mathrm{F}(3.070,89.042)=30.513, \mathrm{p}<0.0005)$ with a partial eta squared of 0.513 .

The results indicated overall significant differences in the means, but to know where those differences occurred, the Bonferroni post hoc test (pairwise comparisons) was utilized (Table 6) to determine which specific means differed.

Table 6: Pairwise comparisons test for measure 3: Variety

\begin{tabular}{|c|c|c|c|c|c|c|}
\hline & \multirow{2}{*}{ (3) Variety } & \multirow{2}{*}{$\begin{array}{c}\text { Mean } \\
\text { Difference (I-J) }\end{array}$} & \multirow{2}{*}{$\begin{array}{l}\text { Std. } \\
\text { Error }\end{array}$} & \multirow{2}{*}{ Sig. ${ }^{b}$} & \multicolumn{2}{|c|}{$\begin{array}{c}\text { 95\% Confidence Interval } \\
\text { for Difference }^{\mathrm{b}}\end{array}$} \\
\hline & & & & & $\begin{array}{l}\text { Lower } \\
\text { Bound }\end{array}$ & $\begin{array}{l}\text { Upper } \\
\text { Bound }\end{array}$ \\
\hline \multirow[t]{4}{*}{1} & 2 & $-.433^{*}$ & 0.104 & 0.002 & -0.749 & -0.118 \\
\hline & 3 & $-.667^{*}$ & 0.111 & 0.000 & -1.003 & -0.330 \\
\hline & 4 & $-1.000^{*}$ & 0.117 & 0.000 & -1.357 & -0.643 \\
\hline & 5 & $-.933^{*}$ & 0.106 & 0.000 & -1.257 & -0.610 \\
\hline \multirow[t]{4}{*}{2} & 1 & $.433^{*}$ & 0.104 & 0.002 & 0.118 & 0.749 \\
\hline & 3 & -0.233 & 0.079 & 0.059 & -0.472 & 0.005 \\
\hline & 4 & $-.567^{\star}$ & 0.092 & 0.000 & -0.846 & -0.287 \\
\hline & 5 & $-.500^{*}$ & 0.115 & 0.002 & -0.849 & -0.151 \\
\hline \multirow[t]{4}{*}{3} & 1 & $.667^{*}$ & 0.111 & 0.000 & 0.330 & 1.003 \\
\hline & 2 & 0.233 & 0.079 & 0.059 & -0.005 & 0.472 \\
\hline & 4 & $-.333^{*}$ & 0.100 & 0.023 & -0.637 & -0.030 \\
\hline & 5 & -0.267 & 0.126 & 0.434 & -0.650 & 0.117 \\
\hline \multirow[t]{4}{*}{4} & 1 & $1.000^{*}$ & 0.117 & 0.000 & 0.643 & 1.357 \\
\hline & 2 & $.567^{*}$ & 0.092 & 0.000 & 0.287 & 0.846 \\
\hline & 3 & $.333^{*}$ & 0.100 & 0.023 & 0.030 & 0.637 \\
\hline & 5 & 0.067 & 0.082 & 1.000 & -0.183 & 0.316 \\
\hline \multirow[t]{4}{*}{5} & 1 & $.933^{*}$ & 0.106 & 0.000 & 0.610 & 1.257 \\
\hline & 2 & $.500^{*}$ & 0.115 & 0.002 & 0.151 & 0.849 \\
\hline & 3 & 0.267 & 0.126 & 0.434 & -0.117 & 0.650 \\
\hline & 4 & -0.067 & 0.082 & 1.000 & -0.316 & 0.183 \\
\hline
\end{tabular}

Based on estimated marginal means.

*. The mean difference is significant at the .05 level.

b. Adjustment for multiple comparisons: Least significant difference (equivalent to no adjustments).

Table 6 shows that the findings obtained using the pairwise comparisons test revealed statistically significant differences in the mean scores of the pre-service mathematics and science teachers' journal writing in the variety dimension. These differences were between the first week and all the other weeks, and there 
were no statistically significant differences in the mean scores of the pre-service teachers' journal writing in the variety dimension between the third week (second measure) and the fifth week (third measure). No statistically significant differences were found between the fifth week (third measure) and the ninth week (fifth measure) or between the seventh week (fourth measure) and the ninth week (fifth measure).

Findings related to the improvement of measure 4: Professionalism As shown in Table 7, the mean scores of the professionalism dimension increased during the clinical experience, from 3.70 to 3.97 .

Table 7: Means and standard deviations of the pre-service teachers' scores in the professionalism dimension

\begin{tabular}{l|l|l}
\hline Professionalism & Mean & $\begin{array}{l}\text { Std. } \\
\text { Deviation }\end{array}$ \\
\hline W1-P & 3.70 & 0.466 \\
\hline W3-P & 3.87 & 0.346 \\
\hline W5-P & 3.90 & 0.305 \\
W7-P & 3.87 & 0.434 \\
\hline W9-P & 3.97 & 0.183 \\
\hline
\end{tabular}

To examine the overall significant difference between the means at the different time points for the professionalism dimension, we utilized the GreenhouseGeisser test to explore the effects within subjects. The results revealed no statistically significant differences among the five mean scores of the professionalism dimension in the reflective journal writing during the 10 weeks of the clinical experience. The findings were analyzed using an ANOVA and repeated measures with a Greenhouse-Geisser correction, revealing that the mean scores for professionalism were not statistically significantly different $(\mathrm{F}(2.128,61.708)=2.704, \mathrm{p}<0.0005)$ with a partial eta squared of 0.085 .

Findings related to the improvement of measure 5: Growth As shown in Table 8, the mean scores of the growth dimension increased during the clinical experience, from 2.07 to 3.27 .

Table 8: Means and standard deviations of the pre-service teachers' scores in the growth dimension

\begin{tabular}{|c|c|c|}
\hline Variety & Mean & $\begin{array}{c}\text { Std. } \\
\text { Deviation }\end{array}$ \\
\hline W1-G & 2.07 & 0.521 \\
\hline W3-G & 2.70 & 0.535 \\
\hline W5-G & 2.97 & 0.414 \\
\hline W7-G & 3.03 & 0.414 \\
\hline W9-G & 3.27 & 0.583 \\
\hline
\end{tabular}

To examine the overall significant difference between the means at the different time points for the growth dimension, we utilized the Greenhouse-Geisser test to explore the effects within subjects. The results found statistically significant 
differences among the five mean scores of the growth dimension in the reflective journal writing during the 10 weeks of the clinical experience. The findings were analyzed using an ANOVA and repeated measures with a Greenhouse-Geisser correction, revealing that the mean scores for growth were statistically significantly different $(\mathrm{F}(3.119,90.462)=26.550, \mathrm{p}<0.0005)$ with a partial eta squared of 0.478 .

The results indicated overall significant differences in the means, but to know where those differences occurred, the Bonferroni post hoc test (pairwise comparisons) was utilized (Table 9) to determine which specific means differed.

Table 9: Pairwise comparisons test for measure 5: Growth

\begin{tabular}{|c|c|c|c|c|c|c|}
\hline & \multirow{2}{*}{ (5) Growth } & \multirow{2}{*}{$\begin{array}{c}\text { Mean } \\
\text { Difference (I-J) }\end{array}$} & \multirow{2}{*}{ Std. Error } & \multirow{2}{*}{ Sig. ${ }^{b}$} & \multicolumn{2}{|c|}{$\begin{array}{c}\text { 95\% Confidence Interval } \\
\text { for Difference }\end{array}$} \\
\hline & & & & & $\begin{array}{l}\text { Lower } \\
\text { Bound }\end{array}$ & $\begin{array}{l}\text { Upper } \\
\text { Bound }\end{array}$ \\
\hline \multirow{4}{*}{\multicolumn{2}{|c|}{1}} & $-.633^{*}$ & 0.155 & 0.003 & -1.105 & -0.162 \\
\hline & & $-.900^{*}$ & 0.121 & 0.000 & -1.267 & -0.533 \\
\hline & & $-.967^{*}$ & 0.122 & 0.000 & -1.338 & -0.596 \\
\hline & & $-1.200^{*}$ & 0.130 & 0.000 & -1.596 & -0.804 \\
\hline \multirow{4}{*}{\multicolumn{2}{|c|}{2}} & $.633^{*}$ & 0.155 & 0.003 & 0.162 & 1.105 \\
\hline & & -0.267 & 0.117 & 0.299 & -0.621 & 0.088 \\
\hline & & -0.333 & 0.138 & 0.226 & -0.754 & 0.087 \\
\hline & & $-.567^{*}$ & 0.149 & 0.007 & -1.020 & -0.113 \\
\hline \multirow{4}{*}{\multicolumn{2}{|c|}{3}} & $.900^{*}$ & 0.121 & 0.000 & 0.533 & 1.267 \\
\hline & & 0.267 & 0.117 & 0.299 & -0.088 & 0.621 \\
\hline & & -0.067 & 0.106 & 1.000 & -0.390 & 0.257 \\
\hline & & -0.300 & 0.128 & 0.264 & -0.689 & 0.089 \\
\hline \multirow{4}{*}{\multicolumn{2}{|c|}{4}} & $.967^{*}$ & 0.122 & 0.000 & 0.596 & 1.338 \\
\hline & & 0.333 & 0.138 & 0.226 & -0.087 & 0.754 \\
\hline & & 0.067 & 0.106 & 1.000 & -0.257 & 0.390 \\
\hline & & -0.233 & 0.079 & 0.059 & -0.472 & 0.005 \\
\hline \multirow{4}{*}{\multicolumn{2}{|c|}{5}} & $1.200^{*}$ & 0.130 & 0.000 & 0.804 & 1.596 \\
\hline & & $.567^{\star}$ & 0.149 & 0.007 & 0.113 & 1.020 \\
\hline & & 0.300 & 0.128 & 0.264 & -0.089 & 0.689 \\
\hline & & 0.233 & 0.079 & 0.059 & -0.005 & 0.472 \\
\hline
\end{tabular}

Based on estimated marginal means.

*. The mean difference is significant at the .05 level

b. Adjustment for multiple comparisons: Least significant difference (equivalent to no adjustments).

Table 9 shows that the findings analyzed using a pairwise comparison revealed statistically significant differences in the mean scores of the pre-service mathematics and science teachers' journal writing in the growth dimension. The differences existed between the first week and all the other weeks and also between the second measure (third week) and the fifth measure (ninth week). 
Meanwhile, there were no statistically significant differences in the growth dimension between the other measures during the clinical experience.

Findings related to the improvement of classroom performance

To examine the improvement of the pre-service mathematics and science teachers' classroom performance, we calculated the means and standard deviations of the CEE survey scores and utilized a paired sample t-test. As shown in Table 10, the findings of the study revealed statistically significant differences between the pre-service teachers' mean scores on the midterm and final CEE surveys regarding their classroom performance in all of the nine domains except for the assessment domain. This result indicates that pre-service mathematics and science teachers did improve their classroom performance during the clinical experience, with statistically significant differences. 
Table 10: Paired samples test for the midterm and final CEE survey measures

\begin{tabular}{|c|c|c|c|c|c|c|c|c|}
\hline & & \multicolumn{5}{|c|}{ Paired Differences } & \multirow[b]{3}{*}{$\mathrm{T}$} & \multirow[b]{3}{*}{$\mathrm{df}$} \\
\hline & & \multirow[b]{2}{*}{ Mean } & \multirow[b]{2}{*}{ Std. Deviation } & \multirow{2}{*}{$\begin{array}{l}\text { Std. } \\
\text { Error } \\
\text { Mean }\end{array}$} & \multicolumn{2}{|c|}{$\begin{array}{l}95 \% \text { Confidence Interval of } \\
\text { the Difference }\end{array}$} & & \\
\hline & & & & & Lower & Upper & & \\
\hline Pair 1 & $\begin{array}{l}\text { Mid - Final CEE: (PLANNING } \\
\text { AND MATERIALS) }\end{array}$ & -0.35000000 & 0.20543385 & 0.038 & -0.427 & -0.27328974 & -9.332 & 29 \\
\hline Pair 2 & $\begin{array}{l}\text { Mid - Final CEE (CLASSROOM } \\
\text { MANAGEMENT) }\end{array}$ & -0.3952381 & 0.1780205 & 0.033 & -0.462 & -0.3287641 & -12.160 & 29 \\
\hline Pair 3 & $\begin{array}{l}\text { Mid - Final CEE: (LANGUAGE, } \\
\text { LITERACY, AND NUMERACY) }\end{array}$ & -0.387500 & 0.218611 & 0.040 & -0.469 & -0.305869 & -9.709 & 29 \\
\hline Pair 4 & $\begin{array}{l}\text { Mid - Final CEE: (LEARNING } \\
\text { ENVIRONMENT) }\end{array}$ & -0.2655555556 & 0.1610509863 & 0.029 & -0.326 & -0.205418129 & -9.031 & 29 \\
\hline Pair 5 & $\begin{array}{l}\text { Mid - Final CEE: (RELEVANCE } \\
\text { AND EXTENSIONS) }\end{array}$ & -0.37333 & 0.22733 & 0.042 & -0.458 & -0.28845 & -8.995 & 29 \\
\hline Pair 6 & $\begin{array}{l}\text { Mid - Final CEE: (INFORMATION } \\
\text { AND } \quad \text { COMMUNICATION } \\
\text { TECHNOLOGY) - }\end{array}$ & -0.36667 & 0.18998 & 0.035 & -0.438 & -0.29573 & -10.571 & 29 \\
\hline Pair 7 & Mid - Final CEE: (ASSESSMENT) & -0.13000 & 0.56976 & 0.104 & -0.343 & 0.08275 & -1.250 & 29 \\
\hline Pair 8 & 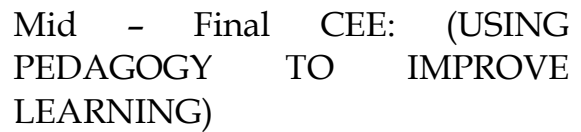 & -0.28667 & 0.14559 & 0.027 & -0.341 & -0.23230 & -10.785 & 29 \\
\hline Pair 9 & $\begin{array}{l}\text { Mid - Final CEE: (SUBJECT AREA } \\
\text { KNOWLEDGE) }\end{array}$ & -0.48333 & 0.18492 & 0.034 & -0.552 & -0.41428 & -14.316 & 29 \\
\hline Pair 10 & $\begin{array}{l}\text { Mid - Final CEE: Classroom } \\
\text { Performance }\end{array}$ & -0.33759 & 0.14672 & 0.027 & -0.392 & -0.28280 & -12.603 & 29 \\
\hline
\end{tabular}


Findings related to the correlation between the improvements in reflective journal writing and classroom performance

To answer the second research question, which asks whether the improvements in reflective journal writing correlated with the improvements in the pre-service teachers' classroom performance, we utilized a linear regression analysis for the data representing the last measures of the mean scores for reflective journal writing and mean scores for the final CEE survey.

The $\mathrm{R}^{2}$ value shows how classroom performance (the dependent variable) influences the independent variable of reflective journal writing. The model summary resulted in an R-value of 0.668 , meaning that $33.1 \%$ of the variation in classroom performance can be explained by reflective journaling. This result represents the simple correlation and indicates an intermediate degree of correlation. In addition, the results of the ANOVA, which expresses how well the regression equation fits the data, indicate that the regression model was able to predict the dependent variable, namely classroom performance, significantly well $(\mathrm{F}(5,24)=3.872, \mathrm{p}<0.0005)$.

The coefficients table (Table 11) provides us with the necessary information to predict classroom performance based on reflective journal writing performance. The results presented in Table 11 reveal that the variety dimension in reflective journal writing contributes to the development of classroom performance with a beta value of 0.508 . This result is statistically significant.

Table 11: The coefficients table

Coefficients $^{\mathrm{a}}$

\begin{tabular}{|c|c|c|c|c|c|}
\hline \multirow[t]{2}{*}{ Model } & \multicolumn{2}{|c|}{$\begin{array}{l}\text { Unstandardized } \\
\text { Coefficients }\end{array}$} & \multirow{2}{*}{$\begin{array}{c}\begin{array}{c}\text { Standardized } \\
\text { Coefficients }\end{array} \\
\text { Beta }\end{array}$} & \multirow[t]{2}{*}{$\mathrm{t}$} & \multirow{2}{*}{ Sig } \\
\hline & B & Std. Error & & & \\
\hline 1 (Constant) & 2.866 & 0.597 & & 4.804 & 0.000 \\
\hline W9-R & 0.023 & 0.069 & 0.063 & 0.339 & 0.737 \\
\hline W9-T & 0.071 & 0.055 & 0.240 & 1.297 & 0.207 \\
\hline W9-V & 0.153 & 0.047 & 0.508 & 3.250 & $0.003^{*}$ \\
\hline W9- P & -0.096 & 0.170 & -0.104 & -0.562 & 0.580 \\
\hline W9- G & 0.067 & 0.055 & 0.235 & 1.222 & 0.234 \\
\hline
\end{tabular}

a. Dependent variable: Final CEE: Classroom Performance

\section{Discussion}

Many researchers assert that developing the individual's ability to reflect is a major component of any teacher preparation program, and since pre-service teachers must 
reflect in order to analyze what they have felt, heard, and seen in their clinical experience, reflection is also an effective tool for developing teachers professionally (Efe, 2009). As a result, researchers' interest in reflective thinking has grown significantly in the past few decades. Yet the literature has not explored the connection between improvement in the five dimensions of pre-service teachers' reflective journal writing (reflectivity, thoroughness, variety, professionalism, and growth) and improvement in their classroom performance during a clinical experience and related to the effect of time. Our study contributes to the literature by making a step in this direction. The results revealed an improvement in most dimensions of reflective journal writing (all except for professionalism) within the 10 -week period, with statistically significant differences $(\mathrm{p}<0.05)$. In addition, the results of the study showed improvement in almost all domains (except for assessment) related to classroom performance within the 10 -week period, with statistically significant differences $(p<0.05)$. This result is consistent with other studies addressing the positive effects of practicing reflective thinking through reflective journal writing on pre-service teachers' classroom performance (Gungor, 2016; Cohen-Sayag \& Fischl, 2012; Rodman, 2010; Gonen, 2016).

In the reflectivity dimension of reflective journal writing, these results show a statistically significant improvement between week one and week nine. Based on the description in the scoring rubric, these results demonstrate that pre-service teachers made improvements in being able to reflect in a way that was deeply thoughtful and provided personal thoughts, feelings, and insights. This result aligns with a study by Gonen (2016), which highlights that practicing reflective thinking skills enhances pre-service teachers' reflectivity. We also noted that although the results revealed overall improvement, there was no significant change between week one and week three or between week five and week seven. This could indicate that pre-service teachers needed more time to make a significant improvement and that two weeks was not quite enough to improve substantially. Another factor that may have affected this result is that the pre-service teachers' clinical experience in the first four weeks focused more on partial teaching in the classroom, so they did not have full teaching responsibility at that time.

In the thoroughness dimension, our results also showed significant improvement in pre-service mathematics and science teachers' reflective journaling between week one and week nine. The differences started between the first week and the third week and continued over the whole period compared with the first measure. This result demonstrates that pre-service teachers became increasingly capable of writing reflections that were substantive, thorough, and provided a detailed view of how they experienced their teaching assignments. Here again, we noticed periods where there was no significant improvement: in the case of thoroughness, improvements began between the third and fifth weeks the fifth and seventh weeks, and the seventh and ninth weeks and the ninth week. As is the case with reflectivity, we suggest that the two-week duration between measuring points was not quite enough to make a significant improvement in thoroughness and that the nature of 
the clinical experience, in which pre-service teachers had increased teaching responsibility after the first four weeks, affected this result.

One of the most interesting findings in this study is that we observed a significant improvement in the variety dimension of reflective journal writing, and this dimension was the only one that significantly correlated with improvement in the pre-service teachers' classroom performance. This result indicates that encouraging pre-service teachers to write narratives on a wide variety of experiences and explore detailed reports on many dimensions of teaching and learning correlates with and contributes statistically to the development of their classroom teaching performance.

This finding aligns with the work of Uline, Wilson, and Cordy (2014), who found that reflection on a wide variety of topics enhances classroom management, teacher flexibility, and time management of pre-service teachers. Furthermore, our result is consistent with other studies addressing the benefits of reflective journal writing, that show it helps teachers in training to modify lessons (Love, 2001), develop a multifaceted view of teaching (Davis, 2006), enhance meta-cognition skills and learning (Cengiz \& Karatas, 2015), and participate in professional development (Hatton \& Smith, 1995).

Our study also showed high levels of professionalism among pre-service science and math teachers. Based on the description of professionalism in the scoring rubric, participants developed their ability to generate reflections that exhibited high confidentiality and ethical standards. They were also found to have great respect for the teaching profession throughout the study. However, this improvement in professionalism was not statistically significant.

Lastly, we found pre-service teachers demonstrated a statistically significant improvement in the growth dimension during the period of the study, meaning that they became increasingly able to write reflections that demonstrated their growth in skill, understanding, and professionalism. Our finding adds to the consensus that because reflective journal writing contributes to pre-service teachers' growth, it should be a focus of teacher training and development (Halliday, 1998; Tomlinson, 1999; Gheith \& Aljaberi, 2018; Al-Shokaa, 2007).

\section{Conclusions}

This study investigated the improvement of reflective journal writing and classroom performance among pre-service mathematics and science teachers during a 10-week clinical experience in their final semester of the Bachelor of Education degree in Primary Education. Our findings demonstrate a significant improvement in both pre-service teachers' reflective writing skills and their classroom performance. These results imply that it would be worthwhile for teacher preparation programs to pay more attention to giving pre-service teachers field-based learning experiences 
that integrate reflective journal writing. We analyzed the five specific dimensions of reflective journal writing (reflectivity, thoroughness, variety, growth, and professionalism) and examined the correlation between each dimension and classroom performance. We observed that the variety dimension contributes significantly to the development of pre-service classroom teaching performance. On this basis, we recommended that more attention be paid to this dimension. When using reflective journals in teacher training, prospective teachers should be encouraged to write narratives on a wide variety of experiences and thoroughly explore their perspectives on the many dimensions of teaching and learning. Such variety in pre-service teachers' journal writing practice will contribute to the development of their classroom teaching performance.

Some results were expected, including our finding that there were no significant differences in pre-service teachers' improvement in writing reflective journals within a short time. We thus recommend that teacher preparation programs give candidates sufficient time for field-based experiences that will allow them to develop their classroom performance and reflective writing skills. Although this study utilized different statistical measures and tests, since it followed the quantitative research approach, there are some limitations such as the size of the study sample and conducting interviews and integrating qualitative data analysis. Thus, more qualitative research is recommended to develop an in-depth understanding of how reflective journal writing might contribute to the development of classroom performance.

\section{References}

Al-Shokaa, A. (2007). Level of Reflective thinking of Undergraduate and Higher Education Students at An-Najah National University. An-Najah University Journal for Research Humanities, 21(4), 1145-1162.

Barbara, M. M., \& Jon, A. L. (2000). Scoring Rubric Development: Validity and Reliability. Practical Assessment, Research E Evaluation, 7(10), 1-6.

Bell, M., \& Gillett, M. (1996). Developing reflective practice in the education of university teachers. Proceedings of the 1996 Annual Conference of the Higher Education and Research Development Society of Australasia (HERDSA), 8 - 12 July, 1996. (pp. 46-52). Perth, Australia: HERDSA.

Berry, K. (1999). Destabilizing educational thought and practice: Post formal pedagogy. In J. L. Kincheloe, S. Steinberg, \& P. H. Hinchey (Eds.) The post formal reader (pp. 330-349). New York: Falmer Press.

Cengiz, C., \& Karatas, F, O. (2015). Examining the effects of reflective journals. Pre-service general chemistry laboratory achievement. Australian Journal of Teacher Education, 40(10), 125-146. https:// doi.org/10.14221/ajte.2015v40n10.8

Creswell, J. W. (2014). Research design: Qualitative, quantitative and mixed methods approaches. London: Sage Publications Ltd.

Cohen-Sayag, E., \& Fischl, D. (2012). Reflective Writing in Pre-Service Teachers' Teaching: What does it Promote?. Australian Journal of Teacher Education, 37(10), 19-36. https://doi.org/10.14221/ajte.2012v37n10.1 
Davis, E. A. (2006). Characterizing productive reflection among pre-service elementary teachers: Seeing what matters. Teaching and Teacher Education, 22, 281-301. https:// doi.org/10.1016/j.tate.2005.11.005

Dewey, J. (1933). How we think: A restatement of the relation of reflective thinking to the educative process. New York: D.C. Heath.

Efe, R. (2009). Science student teachers' attitudes towards reflective practice: Differences in subjects and grades. Cypriot Journal of Educational Sciences, 4, 72-86.

Gheith, E., \& Aljaberi, N. (2018). Reflective teaching practices in teachers and their attitudes toward professional self-development. International Journal of Progressive Education, 14(3), 160-179. https://doi.org/10.29329/ijpe.2018.146.11

Gikandi, J. (2013). How an open online reflective journal enhance learning in teacher education? Journal of Technology and Teacher Education. 21(1), 5-26.

Göker, \& Süleyman. (2016). Use of Reflective Journals in Development of Teachers' Leadership and Teaching Skills. Universal Journal of Educational Research, 4(12A), 6370. https:// doi.org/10.13189/ujer.2016.041309.

Gonen, S. I. (2016). A Study on Reflective Reciprocal Peer Coaching for Pre-service Teachers: Change in Reflectivity. Journal of Education and Training Studies, 4(7), 211-225. https://doi.org/10.11114/jets.v4i7.1452

Greenhous-Geisser. (n.d.). Retrieved from https://www.scalelive.com/greenhousegeisser.html.

Gungor, M. N. (2016). Turkish Pre-service Teachers' Reflective Practices in Teaching English to Young Learners. Australian Journal of Teacher Education, 41(2), 136-151. https://doi.org/10.14221/ajte.2016v41n2.9

Halliday, J. (1998). Technicisim, reflective practice, and authenticity in teacher education. Teaching and Teacher Education, 14(6) 597- 605. https://doi.org/10.1016/s0742051x(98)00010-9

Hatton, N., \& Smith, D. (1995). Reflection in teacher education: Towards definition and implementation. Teaching and Teacher Education. 11(1), 33-49. https:// doi.org/10.1016/0742-051x(94)00012-u

Heichel, L. G., \& Miller, T. M. (1993). The importance of reflection in decision-making. In L. Patterson, et. al. (Eds.), Teachers are researcher: Reflections and action (pp. 173-182). Newark, DE: International Reading Association.

Henter, R., \& Indreica, E. S. (2014). Reflective journal writing as a metacognitive tool. In AFASES International Conference. Retrieved March 10, 2015, from http://213.177.9.66/ro/afases/2014/socio/henter_indreica.pdf.

Isikoglu, N. (2007). The role of reflective journals in early childhood pre-service teachers' professional development. Educational Sciences: Theory and Practice, 7(2), 819-825.

Knapp, N, F. (2012). Reflection journals: Making construction use of the "apprenticeship of observation" in pre-service teacher education. Teaching Education, 23(3), 323-340. http:/ / doi.org/10.1080/10476210.2012.686487

Love, (2001). Reflective journal writing in an inquiry-based science course for elementary pre-service teachers. Paper presented at the Annual International Meeting of the National Association for Research in Sciences. St. Louise, Mo.

Lindroth, J. (2015). Reflective Journals: A Review of the Literature. Applications of Research in Music Education, 34(1), 66-72.

Morrison, G. (2009). Early childhood education today. Upper Saddle River, NJ: Pearson. 
Risko, V., Roskos, K., \& Vukelich, C. (2002). Prospective teachers' reflection: Strategies, qualities, and perceptions in learning to teach. Reading Research and Instruction, 41, 149-179. https:/ / doi.org/10.1080/19388070209558363

Rodman, G. J. (2010). Facilitating the Teaching-learning Process Through the Reflective Engagement of Pre-service Teachers. Australian Journal of Teacher Education, 35(2), 20-35. https://doi.org/10.14221/ajte.2010v35n2.2

Sempowicz, T., \& Hudson, P. (2012). Mentoring pre-service teachers' reflective practices to produce teaching outcomes. International Journal of Evidence Based Coaching and Mentoring, 10(2), 52-64.

Shoffner, M. (2008). Informal reflection in pre-service teacher education. Reflection Practices, 9 (2), 123-134. https://doi.org/10.1080/14623940802005392

Swafford, J. O., Jones, G. A., Thornton, C. A., Stump, S. L., \& Miller, D. R. (1999). The impact on instructional practice of a teacher change model. Journal of Research \& Development in Education, 32(2), 69-82.

Tomlinson, P. (1999). Conscious reflection and implicit learning in teacher preparation. Oxford Review of Education, 25(4), 533-544.

https://doi.org/10.1080/030549899103973

Uline, C., Wilson, J. \& Cordry, S. (2004). Reflective journals: a valuable tool for teacher preparation. Education, 24(3), 456-459. 